\title{
THE FUNCTIONAL LATERALIZATION AND COMPUTER DYNAMIC POSTUROGRAPHY
}

\section{Marek Tomaszewski ${ }^{1}$, Grażyna Olchowik ${ }^{2}$, Piotr Olejarz ${ }^{3}$, Monika Tomaszewska ${ }^{4}$}

\author{
${ }^{1}$ Department of Human Anatomy, Medical University of Lublin, Poland \\ ${ }^{2}$ Department of Biophysics, Medical University of Lublin, Poland \\ ${ }^{3}$ Department of Otolaryngology and Laryngeal Oncology, SPSK-4, Lublin \\ ${ }^{4}$ I Department of Radiology, Medical University of Lublin
}

Tomaszewski M., Olchowik G., Olejarz P., Tomaszewska M. (2014), The functional lateralization and computer dynamic posturography. Health Problems of Civilization, 4 (8), p. 20-26

Summary: Disorders in the functioning of the human body balance system exist in 20-30 \% of adults and in 8-18\% of children. The main causes of these aberrations are: benign positional vertigoes, migraine, anxiety disorders and depression, cerebrovascular diseases, brain traumas, labyrinthitis, toxic impairment of labyrinth, vestibular neuronitis, Ménière disease, brain tumours. Among the minor causes of these disorders are: internal ear disorders, inner ear circulation disorders, sclerosis multiplex (SM), epilepsy, arterial hypertension, postural hypertension, heart rhythm disorders, sclerosis, hypoglycaemia and involutional alternations (see: prezbiastazja). Human body balance disorders increase the risk of falls, which may threaten health and life. Frequency of these disorders raises with age, which is the cause of progressing degeneration of all the anatomical and functional systems, the efficiency of which affects the stability of the human body. Determination of the factors, which are related to a worse functioning of the body balance system of young people, who do not experience any clinical symptoms caused by this system is vital, especially in preventing falls and complications attributed to them. It allows to implement possibly early the preventive actions substantial for people encumbered by the risk factors. The aforesaid actions may consist in the alternation of a given factor (diet, sleep, physical activity). In case of the factors, which are not subject to modifications (i.e. heterogeneous form of the functional lateralization), it is essential to prevent potential diseases that disturb the functioning of the body balance system, which is already impaired.

This study aimed to acquaint with the findings concerning the evaluation of the functional lateralization enriched with a new diagnostic tool - a computerized dynamic posturography.

The computerized dynamic posturography (CPD) is a state-of-the-art and faultless evaluation tool of the functional lateralization. It provides a comprehensive knowledge, which concerns not only the preferences of the body, but also constitutes an objective and quantitative diagnostic method for the disorders in the functioning of the body balance system. CPD differentiates a few clinical protocols: the Sensory Organization Test (SOT); the Motor Control Test (MCT); the Adaptation Test (ADT). SOT evaluates the control of the body balance in different conditions (eyes closed/eyes opened; environment moves/ground moves) of the sensory systems stimulation. MCT assesses the postural reactions (body postures) in response to an unexpected changes in the location of the feet prop surface. ADT assesses the efficiency of the adaptation mechanisms in the body balance control.

Keywords: functional lateralization, computerized dynamic posturography, body balance

\section{Introduction}

Disorders in the functioning of the human body balance system exists in $20-30 \%$ of adults and in 8-18\% of children (Narożny et al. 2010). The main causes of these aberrations are: benign positional vertigoes(30\%), migraines(10-15\%), anxiety disorders and depression(10-15\%), cerebrovascular diseases(10\%), brain traumas(10\%), labyrinthitis(5\%), toxic impairment of the labyrinth(5\%), vestibular neuronitis(3-6\%), Ménière disease $(3 \%)$, brain tumours $(<2 \%)$. Among the minor causes of these disorders are: internal ear disorders, inner ear circulation disorders, sclerosis multiplex (SM), epilepsy, arterial hypertension, postural hypertension, heart rhythm disorders, sclerosis, hypoglycaemia and involutional alternations (see: prezbiastazja) (Prusiński 2009, 2010).

Body balance disorders increase the risk of falls, which may threaten health and life (Davis et al. 2011; Viswanathan, Sudarsky 2011). Frequency of these disorders raises with age, which is the cause of progressing degeneration of all the anatomical and functional systems, the efficiency of which affects the stability of the human

Adress for correspondence: Marek Tomaszewski, Department of Human Anatomy, Medical University of Lublin, Al. Racławickie 1, 20-059 Lublin, e-mail: tomaszewski.marek@gmail.com, phone: 48817423681

Tables: 2 Figures: 0 References: 22 Full-text PDF www.hpc.edu.pl Copyright (C) Pope John Paul II State School of Higher Education in Biała Podlaska, Sidorska 95/97, 21-500 Biała Podlaska Indexation: Index Copernicus, Database AGR0, ProQuest, Polish Ministry of Science and Higher Education. This is an open-access article distributed under the terms of the Creative Common Attribution Non-commercial license (http://creativecommons.org/licenses/by-nc/3.0), which permits use, distribution and reproduction in any medium, provided the original works is properly cited, the use is non-commercial and is otherwise in compliance with the license. 
body. The risk of a fall, which ends with death in the group of people who have turned 65 years old is seven times higher than in the group of young people. From 5 to $15 \%$ of falls end up in broken, dislocated limbs and severe head trauma as well as damage of soft tissues (Błaszczyk, Czerwosz 2005).

This study aimed to acquaint with findings concerning the evaluation of the functional lateralization enriched with a new diagnostic tool - a computerized dynamic posturography.

\section{Functional lateralization}

The notion of the lateralization (in other words asymmetry) specifies the lateral dominance, which concerns paired body organs as well as the mental functions of the brain (Mroziak 1992). Functional lateralization, which relates to paired body organs, determines the efficiency dominance and the propensity for a frequent use of one of them e.g. right or left limb. It is connected with the dominance of the centres representing the given organ in one of the cerebral hemispheres (Bogdanowicz 1989; Osiński 2003). The efficiency dominance and propensity for using right hand, eye, leg is called: right-handedness, right-sightedness and right-leggedness, respectively. The dominance concerning left side of the body is referred to as: left-handedness, left-sightedness and left-leggedness. Lack of functional dominance of the one body side over the other is defined as binocularity, ambidexterity, bipedalism (Osiński 2003). Taking into account a direction of the respective locomotor organs and senses lateralization, it is called a form of lateralization, a model of dominance or an asymmetry profile. There are the following models of the functional lateralization differentiated: homogenous (left or right-sided) or heterogeneous (hybrid or unspecified) (Osiński 2003; Bogdanowicz 1989).

In the model of homogenous dominance - along with right-handedness there occurs right-sightedness and right-footedness. Left-handedness appears exclusively in connection with left-sightedness and left-footedness. Within the heterogeneous unspecified lateralization model (weak) there exists a lack of dominance in respect to one of the paired organs (Osiński 2003; Bogdanowicz 1989).

Functional asymmetry appears during conduction of activities that require usage of only one of the paired organs. While being involved in the activities that engage a paired organ belonging to the right or left side of the body e.g. both upper limbs, lateralization emerges when it is necessary for one of them to become dominant. Then, a dominant organ becomes a leading one, while the second plays an auxiliary role (Osiński 2003).

When assessing a formation of the functional lateralization, the model of lateralization, pace of its development and neurophysiological background have to be included in this process. Models of homogenous lateralization, both left-sided and right-sided are deemed proper ones. They are related to a dominance of one of the brain hemispheres. We talk about abnormal models of lateralization in case of the heterogeneous profile of lateralization, both unspecified and hybrid as well (Bogdanowicz 1989).

Functional dominance that concerns a paired vestibular organ is set as early as at the fetal stage, which has an impact on the further development of functional lateralization of limbs (Previc 1991). Golomer and Mbongo (Golomer, Mbongo 2004) have observed that people with different preferences for using lower limbs, are led by distinct mechanisms of body balance control while standing on one limb. According to other scientists (Bogdanowicz 1989; Iteya, Gabbard 1996; Rengstorff 1967) the aberrations of perception, spatial orientation and motor coordination, which are substantial for the proper body balance control can be observed more frequently in people with heterogeneous form of functional lateralization.

\section{An evaluation of the functional lateralization}

An evaluation of the functional lateralization (eye, upper and lower limb) involves usage of an adequately prepared medical examinations (Osiński 2003; Zazzo, Galifret-Granjon 1974; Malinowski, Wolański 1988).

In order to establish the dominance of the upper limb, the examined subjects were asked to: pick up the box of matches, write down one's name with the pencil on the sheet of paper, throw a tennis ball. At the beginning of each task, the objects that were used in the examination lied on the table, in front of which the examined person stood. Distance between the object and the left and right hand of the participant was equal (Osiński 2003; Zazzo, Galifret-Granjon 1974; Malinowski, Wolański 1988).

Aiming at establishing the dominance of the lower limb, the participants of the experiments were asked to: move feet as if writing the letter " $\mathrm{D}$ " on the sand, stand on the wooden step of $30 \mathrm{~cm}$ height, kick the box of matches that lies on the floor. At the beginning of the second and third task, a participant stood in the position, in which the distance between his left/right foot and the wooden step and the box of matches was equal. A limb, which the participant put on the step in the first place was deemed dominant (Osiński 2003; Zazzo, Galifret-Granjon 1974; Malinowski, Wolański 1988). 
When a participant used the same upper or lower limb in each of the three tasks, dominance of the said limb was recognized. If during next three examinations the examinee used interchangeably left or right, upper or lower limb, the surveys in the form of table proposed by Osiński (Osiński 2003) were used (Table no. 1 and no. 2).

Table no. 1 includes commands for the participants (holding the pen, spoon, toothbrush, scissors, knife, matches while lighting, ball while throwing it, hammer while hammering the nail), which concern the activity of the upper limb (RG- right, LF - left). The results presented within the following range of points: 36 - 40 points indicate a clear right-handedness, 29 - 35 points indicate a weak right-handedness, 20 - 28 points suggest ambidexterity, 13 - 19 points reflect weak left-handedness and 8-12 points suggest clear left-handedness.

Table 1. The evaluation of the upper limb functional lateralization (Osiński 2003)

\begin{tabular}{|l|l|l|l|l|l|}
\hline Upper limb activity & $\begin{array}{c}\text { Always RG } \\
-5 \text { points }\end{array}$ & $\begin{array}{c}\text { often RG } \\
-4 \text { points }\end{array}$ & $\begin{array}{c}\text { equally } \\
\text { frequent } \\
-3 \text { points }\end{array}$ & $\begin{array}{c}\text { the most fre- } \\
\text { quently LF } \\
-2 \text { points }\end{array}$ & $\begin{array}{c}\text { always LF } \\
-1 \text { point }\end{array}$ \\
\hline writing with a pen & & & & & \\
\hline eating with a spoon & & & & & \\
\hline brushing teeth with a toothbrush & & & & & \\
\hline cutting paper with scissors & & & & & \\
\hline slicing bread with a knife & & & & & \\
\hline lighting a match & & & & & \\
\hline throwing a ball & & & & & \\
\hline hammering a nail & & & & & \\
\hline
\end{tabular}

Table 2 contains the commands for the research participant (bounce before the long jump, entering a very high step, hitting the ball towards goal, long-lasting jumps on one leg, test of writing a specific letter with one's foot on the floor, standing on one leg in the "flamingo" position) regarding the activities of the lower limb (PN right, LN - left). Results in the range of 27 - 30 are a clear right footedness, 22 - 26 poor right footedness, 15 - 21 ambidekstria, 10 - 14 weak left footedness, 6 - 9 clear left footedness.

Table 2. Assessment of functional lateralization of the lower limbs (Osiński 2003)

\begin{tabular}{|l|l|l|l|l|l|}
\hline Lower limb activity & $\begin{array}{c}\text { always PN } \\
-5 \text { points }\end{array}$ & $\begin{array}{c}\text { Most often PN } \\
-4 \text { points }\end{array}$ & $\begin{array}{c}\text { Equally often } \\
-3 \text { points }\end{array}$ & $\begin{array}{c}\text { Most often LN } \\
-2 \text { points }\end{array}$ & $\begin{array}{c}\text { always LN } \\
-1 \text { point }\end{array}$ \\
\hline bounce before long jump & & & & & \\
\hline entering a very high step & & & & & \\
\hline hitting the ball towards goal & & & & & \\
\hline long-lasting jumps on one leg & & & & & \\
\hline $\begin{array}{l}\text { test of writing a specific letter } \\
\text { with one's foot on the floor }\end{array}$ & & & & & \\
\hline $\begin{array}{l}\text { balance test-standing } \\
\text { on one leg in the „flamingo" position }\end{array}$ & & & & & \\
\hline
\end{tabular}

Right-handedness was diagnosed when the total score of points was at least 29, left-handedness- when the result did not exceed 19. Right footedness was diagnosed, however, when the result was at least 22, while left footedness when it did not exceed 14. In other cases, the lack of a functional limb dominance was diagnosed, the so called ambidexterity or bi-footedness (Osinski 2003).

In order to determine the eye dominance the Miles test is applied (Roth et al. 2002).The test participant was requested to do the following:

- put his hands in such a way as to create a gap between them in the shape of a triangle (the thumb of one hand covers the thumb on the other, the remaining fingers of one hand crossed fingers on the other, the gap should be such that when he brings his hands to his face he could see it only with one eye);

- straighten hands in elbows and lift his hand so that the gap was found at the level of the eyes;

- select any object located about 3 feet away, so that it is completely visible through a slot (the test participant cannot at this moment close his left or right eye); 
- observe the object through the gap, and a very slow convergence of his hands until they touch the face (the whole time the left and right eye of the test participant should be open and the object cannot disappear for a moment from the limited by the slit view).

The eye, in front of which there was the gap between both hands once they got closer to the face, was considered the dominant one. In the case of vision defects participants joined the research in their own glasses or corrective contact lenses. Taking into account the observations of Zazzo and Galifret-Granjon (Zazzo, Galifret-Granjon 1974) according to which the ambivalence with regard to the eyes in case of healthy people aged above 14 years old is very rare, it was determined whether it is the left eye or the right eye which dominates, based on the result of a sample performed once.

\section{Computer dynamic posturography (CDP)}

Computer dynamic posturography is an objective and quantitative diagnostic method of disorders of the balance system of the human body. It was approved by the World Health Organization (WHO) and it meets the criteria of the International Classification of Functioning, Disability and Health (ICF). CDP has been defined by the American Academy of Neurology (AAN) and the American Academy of Otolaryngology, Head and Neck Surgery (AAO-HNS) as a method of enabling quantitative assessment (Nashner 1976; Nashner 1993a, 1993b, 1993c, 2008a Interna NeuroCom, 2008b):

- usefulness of the information of the organ of vision (sight), vestibular organ (balance), the somatosensory system (sensation of body position) in controlling the balance of the human body

- a mechanism of central sensory integration, allowing proper use of the information obtained from sense organs

- motor strategy used in response to balance disorders

- quantities characterizing the motor reactions, affecting the efficacy of postural responses.

In 1986, the American Agency on Food and Drug Administration (FDA) authorized the CDP device introduction onto the medical market.

In CDP a number of research protocols may be identified. These include sensory organization test (SOT), motor control test (MCT), the test of adaptation (ADT). Within SOT control of balance under different conditions is evaluated (eyes closed /eyes open, moving environment / moving surface) stimulating sensory systems (sensory). MCT assesses postural reactions (postures) in response to unexpected changes in the position of the foothold. The ADT estimates the efficiency of adaptive mechanisms in the control of body balance (Nashner 1976; Nashner 1993a, 1993b, 1993c, NeuroCom Interna 2008a, 2008b).

Sensory Organization Test

The Sensory Organization Test (SOT) consists of: body balance analysis (ES), sensory analysis (SRS), analysis of motor strategies (MS) and analysis of the countervailing position of the center of gravity of the body (COG AS) (Nashner 1976; Nashner 1993a, 1993b, 1993c , NeuroCom Interna 2008a, 2008b).

Result of the analysis of the balance of the body (ES) provides a quantitative assessment of the deviation of center of gravity of the body in the anterior-posterior direction. ES values for each sample are presented on a percentage scale. A score of $100 \%$ means that there is no deviation of the body center of gravity in the anteriorposterior direction. The greater the extent of these deviations the less the value of the outcome analysis of the balance of the body (Nashner 1976; Nashner 1993a, 1993b, 1993c, NeuroCom Interna 2008a, 2008b).

The results of sensory analysis (SRS) are calculated by a computer program and presented separately for the somatosensory system (SOM), visual organ (VIS), vestibular organ (VES), visual preferences (PREF). These results demonstrate the utility of the signal from the sensory system in the control of body balance. They are presented in a percentage scale. A value of $100 \%$ means full efficiency of the given sensory system and the proper use of the signal from this system in the control of body balance (Nashner 1976; Nashner 1993a, 1993b, 1993c, NeuroCom Interna 2008a, 2008b).

The result of the motor strategy (MS) provides a quantitative assessment of muscle activity responsible for the movements in the ankle joints and muscle activity responsible for the movement of one's hips during each SOT test trial. The higher the MS value the higher muscle activity responsible for ankle movement, compared to the activity of the muscle responsible for the movements of the hip joints. The smaller the MS value, the greater the muscle activity responsible for movement in the hip joints compared to the activity of the muscles responsible for the movements of the ankle joints (Nashner 1976; Nashner 1993a, 1993b, 1993c, Interna NeuroCom 2008a, 2008b).

Result of the analysis of the position of the countervailing center of body gravity (COG AS) of the person examined is presented for each sample using two values expressed in angle degrees CAX and CAY. The former of these is the angle of deviation of center of body gravity from the equilibrium position in the frontal plane and the other one in the sagittal plane. They are calculated on the basis of measurements of the angle of deviation from the center of body gravity from 
the equilibrium position recorded during the 20s during each test. A positive value of the angle corresponds to the deviation of the center of gravity toward the right and to the front, and a negative value to the left and to the back relative to the equilibrium position (Nashner 1976; Nashner 1993a, 1993b, 1993c, NeuroCom Interna 2008a, 2008b).

\section{Motor control test}

In the motor control test (MCT) tensometric plates are moved by cylinders within the platform in a horizontal plane posturograph. This movement is independent from the variations of the person's center of gravity. Aperture constituting the visual environment is stationary. MCT test is carried out in six motion variants of tensometric plates conditions: weak translation (SFT), weak retrograde motion (SBT), average translation (MFT), average retrograde motion (MBT), strong translation (LFT), strong retrograde motion (LBT). Moving the tensometric plates causes deviation of the center of gravity of the body. The direction of such a deviation is opposite to the direction of the plates' movement. Movement of the plates is therefore a destabilizing stimulus. Range of shifts of these plates is chosen to match the height of the tested person. This is to serve giving the center of gravity of the body the same angular velocity for people of different heights. This causes postural response, which is assessed within the test. Within the test of motor control - MCT the following aspects are analyzed: symmetry of distribution of the body weight (WS), response latency (L), the amplitude of response (A), symmetry of responses (AS) (Nashner 1976; Nashner 1993a, 1993b, 1993c, NeuroCom Interna 2008a, 2008b ).

Result of the analysis of the symmetry of body weight distribution (WS) provides a quantitative assessment of the load of both lower limbs. In the case of symmetrical loading of the lower extremities the value RF + RR is equal to the value LF + LR. Result of the analysis of the symmetry of load distribution achieves at that point a value of 100 score points. Result greater than 100 indicates a higher load of the right limb, and a result less than 100-of the left one (Nashner 1976; Nashner 1993a, 1993b, 1993c, NeuroCom Interna 2008a, 2008b).

Result of the analysis of response latency (L) allows to mark the time that elapses between the beginning of the moving of tensometric plates and the beginning of postural responses in milliseconds. Latency response is established, accordingly for the left and right limb (Nashner 1976; Nashner 1993a, 1993b, 1993c, 2008a Interna NeuroCom, 2008b):

- A weak translation movement of the tensometric plates (LLSFT, LRSFT);

- An average translation movement of the tensometric plates (LLMFT, LRMFT);

- A large translation movement of the tensometric plates (LLLFT, LRLFT);

- A weak retrograde movement of the tensometric plates (LLSBT, LRSBT);

- An average retrograde movement of the tensometric plates (LLMBT, LRMBT);

- A large retrograde movement of the tensometric plates (LLLBT, LRLBT).

On the basis of these values, the computer system calculates the cumulative result of the analysis of postural response latency (LC) (Nashner 1976; Nashner 1993a, 1993b, 1993c, 2008a NeuroCom Internal Medicine, 2008b).

Result of the analysis of amplitude of responses (A) allows to evaluate the effect of postural responses expressed in \% $\%$. Amplitude of response is determined appropriately for the left and right limb (Nashner 1976; Nashner 1993a, 1993b, 1993c, 2008a Interna NeuroCom, 2008b):

- A weak translation movement of the tensometric plates (ALSFT, ARSFT);

- An average translation movement of the tensometric plates (ALMFT, ARMFT);

- A large translation movement of the tensometric plates (ALLFT, ARLFT);

- A weak retrograde movement of the tensometric plates (ALSBT, ARSBT);

- An average retrograde movement of the tensometric plates (ALMBT, ARMBT);

- A large retrograde movement of the tensometric plates (ALLBT, ARLBT).

Result of the analysis of the symmetry responses (AS) provides a quantitative assessment of the amplitude of the response of the left lower limb with respect to the amplitude of the response of the right lower limb. The result of symmetry of the response equal to 100 means equal values of amplitudes of responses of both lower limbs. Score greater than 100 indicates a greater amplitude of response of the right limb, and score of less than 100- of the left lower limb (Nashner 1976; Nashner 1993a, 1993b, 1993c, NeuroCom Interna 2008a, 2008b).

\section{Test of adaptation}

In the test of adaptation (ADT) the tensometric plates are deflected from the horizontal plane by the actuators in the platform of posturograph, regardless of the variations of gravity of the body. The aperture constituting the visual environment is stationary. The angular velocity of movement of the plates is $20 \%$ s. Movement of the plates causes a change in the angle of the placement of the ankle by $8^{\circ}$ within the time of $400 \mathrm{~ms}$ (Nashner 1976; Nashner 1993a, 1993b, 1993c, NeuroCom Interna 2008a, 2008b).

The test consists of two series. In each of these, five tests are performed. In one series the orientation change of tensometric plates causes flexion in the ankle (ATU). In the second series, the orientation change of tensometric plates causes straightening of the ankle (ATD). Stretch reflex triggered within the first trial of both series increases muscle tension and stiffness of the ankle. When tensometric plates deflect from the horizontal plane, it increases 
the deviation of the center of body gravity from the equilibrium position. In the subsequent four attempts complex adaptive mechanisms should lead to a reduction in the amplitude of muscles cramps which act destabilizing and are a result of tensile-induced reflex (Nashner 1976; Nashner 1993a, 1993b, 1993c, NeuroCom Interna 2008a, 2008b).

In the test of adaptation a sway energy is determined (SE) after each deflection of the tensometric plates. It allows for a quantitative assessment of the size of the deviation of center of gravity of the body at the time of its return to the equilibrium position (Nashner 1976; Nashner 1993a, 1993b, 1993c, NeuroCom Interna 2008a, 2008b).

Sway energy (SE) is therefore the weighted sum of mean square of velocity and acceleration of movement of the point of application of the vertical component of the impact of both feet (that is resultant of vertical components of the impact forces of both feet) onto tensometric plates in the anterior-posterior direction in the time of $2 \mathrm{~s}$ return of center of gravity of a examined person's body to the position of equilibrium after a sudden deflection of tensometric plates. Sway energy (SE) is a dimensionless parameter and takes values from 0 to 200 . Its value may be greater, with an increase of the deviation of the center of gravity of the body at the time of return to the equilibrium position, and thus, with an increase of the imbalance in the body caused by deviation of the tensometric plates (Nashner 1976; Nashner 1993a, 1993b, 1993c, NeuroCom Interna 2008a, 2008b).

\section{Summary}

Computer dynamic posturography is a modern and superior method of assessing the functional lateralization. Supplemented with older research tests it gives a lot of knowledge about not only the preferences of the body, but also about an objective and quantitative diagnostic method of balance system disorders of the human body.

Determining the factors associated with worse functioning of the body balance system in young people without clinical symptoms on the part of the system is important in the prevention of falls and their complications in the elderly age. This allows for the timely implementation of preventive measures in patients burdened with these factors. Prevention may involve modification of a given factor (diet, sleep, physical activity). In the case of factor which are not subject to modification (ie. heterogeneous forms of functional lateralization) preventing additional illnesses which disrupt the work of the already worse functioning balance system becomes increasingly important.

\section{References:}

1. Błaszczyk JW, Czerwosz L. (2005), Stabilność posturalna w procesie starzenia. Gerontol Pol. 13, s. 25-36.

2. Bogdanowicz M. (1989), Leworęczność u dzieci. Warszawa, WSiP.

3. Davis JC, Marra CA, Liu-Ambrose TY. (2011), Falls-related self-efficacy is independently associated with qualityadjusted life years in older women. Age Ageing. 40, s. 340-346.

4. Golomer E, Mbongo F. (2004), Does footedness or hemispheric visual asymmetry influence centre of pressure displacements? Neurosci Lett. 367, s. 148-151.

5. Iteya M, Gabbard C. (1996), Laterality patterns and visual-motor coordination of children. Percept Mot Skills. 83, s. 31-34.

6. Malinowski A, Wolański N. (1988), Metody badań w biologii człowieka. Warszawa, PWN.

7. Mroziak J. (1992), Równoważność i asymetria funkcjonalna półkul mózgowych. Warszawa: Seria wydawnicza Wydziału Psychologii Uniwersytetu Warszawskiego.

8. Narożny W, Siebert J, Wojtczak R. (2010), Epidemiologia zawrotów głowy i zaburzeń równowagi. Forum Med Rodz. 4, s. 356-365.

9. Nashner LM. (1976), Adapting reflexes controlling the human posture. Exp Brain Res. 26, s. 59-72.

10. Nashner LM. (1993a), Computerized Dynamic Posturography. In: Jacobson GP, Newman CW, Kartush JM, ed. Handbook of balance function testing. St. Louis: Mosby Year-Book, s. 280-307.

11. Nashner LM. (1993b), Computerized Dynamic Posturography: Clinical Applications. [In:] Jacobson GP, Newman CW, Kartush JM, ed. Handbook of balance function testing. St. Louis: Mosby Year-Book, s. 308-334.

12. Nashner LM. (1993c), Practical Biomechanics and Physiology of Balance. In: Jacobson GP, Newman CW, Kartush JM, ed. Handbook of balance function testing. St. Louis: Mosby Year-Book, s. 261-279.

13. NeuroCom International. (2008a), Balance Manager Systems. Clinical Interpretation Guide. NeuroCom International, Inc., Clakamas (Or).

14. NeuroCom International. (2008b), Balance Manager Systems. Clinical Operations Guide. NeuroCom International, Inc., Clakamas (Or).

15. Osiński W. (2003), Symetria i asymetria amotoryczność człowieka. W: Osiński W, red. Antropomotryka. Poznań: Akademia Wychowania Fizycznego, s. 286-301. 
16. Previc FH. (1991), A general theory concerning the prenatal origins of cerebral lateralization in humans. Psychol Rev. 98, s. 299-334.

17. Prusiński A. (2010), Diagnostyka zawrotów głowy. W: Obrębowski A, red. Standardy rozpoznawania i leczenia zawrotów głowy. Warszawa, Oinpharma Sp. Z00, s. 96-104.

18. Prusiński A. (2009), Zawroty głowy: wciq̨ż aktualny problem kliniczny. Neur Prakt. 9, s. 15-19.

19. Rengstorff RH. (1967), The types and incidence of hand-eye preference and its relationship with certain reading abilities. Am J Optom Arch Am Acad Optom. 44, s. 233-238.

20. Roth HL, Lora AN, Heilman KM. (2002), Effects of monocular viewing and eye dominance on spatial attention. Brain. 125, s. 2023-2035.

21. Viswanathan A, Sudarsky L. (2011), Balance and gait problems in the elderly. Handb Clin Neurol. 103 , s. 623-634.

22. Zazzo R, Galifret-Granjon N. (1974), Geneza i formuły lateralizacji. W: Zazzo R, red. Metody psychologicznego badania dziecka. Warszawa, PZWL, t. II, s. 2-32.

Submitted: 31.07 .2014

Accepted: 01.09.2014 